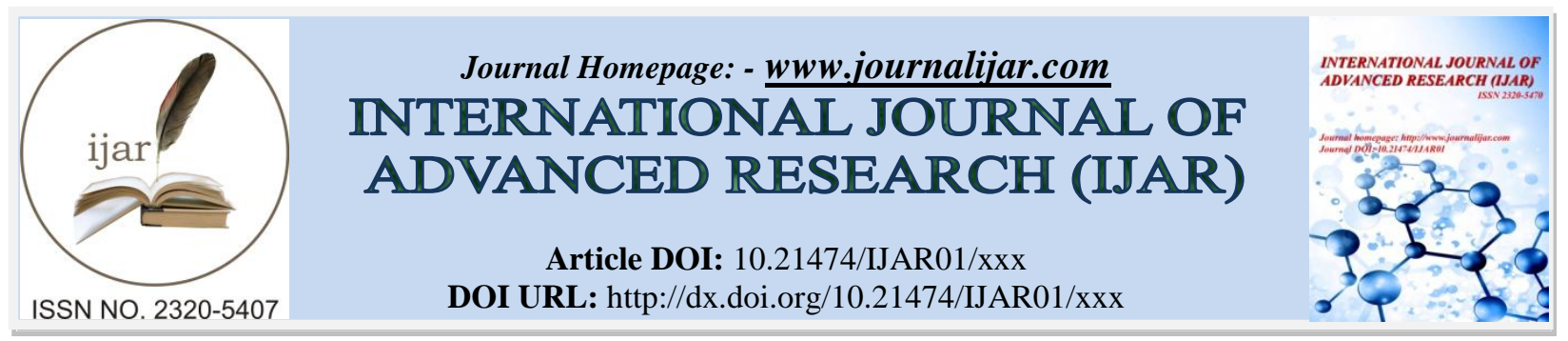

RESEARCH ARTICLE

\title{
AWARENESS OF SAUDI POPULATION IN MADINA REGION ABOUT ATTENTION DEFICIT HYPER-ACTIVE DISORDER (ADHD) IN CHILDREN.
}

\author{
Khaled Alghamdi ${ }^{1,2}$, AbrarAlharbi ${ }^{3}$, Abdul-Qader Susi ${ }^{3}$ and Tafani Thani ${ }^{3}$. \\ 1. Department of pediatrics, Taibah University, Medina, Saudi Arabia \\ 2. Department of Pediatrics, McMaster University, Hamilton, ON, Canada. \\ 3. Medical Students, Taibah University, Medina, Saudi Arabia.
}

\section{Manuscript Info}

Manuscript History

Received: 25 December 2016

Final Accepted: 25 January 2017

Published: February 2017

\section{Abstract}

Introduction: Attention Deficit Hyper-Active Disorder (ADHD) is one of the most common neurobehavioral developmental disorders among children. The prevalence of ADHD in all Arabic countries in general was ranging from $1.3 \%$ to $16 \%$ compared to $4-8 \%$ in US. While in Korea it was between $7.6 \%$ to $9.5 \%$. However, the prevalence was reached $20 \%$ in India.

Methodology: A cross sectional study has been set in Saudi Arabia, Madina Region. The study population included both genders from 15 years and above, people living outside Madina and those whom are in the medical field have been excluded.Data were analyzed by the SPSS version 20.

Results: . $25.1 \%$ knew the disease through their experience with an ADHD patient known to them. $14.7 \%$ read about ADHD through medical websites, $7,3 \%$ and $7.6 \%$ knew about it from newspapers and social media, respectively. $71.3 \%$, believed that ADHD is a real disease, $22 \%$ believe that it is a behavioral disorder, $16 \%$ consider it as a neurological disease while $18 \%$ considered it as a psychiatric disorder. On the other hand, $31.8 \%$ believe that ADHD is a mixed disorder and only $11 \%$ did not know anything about the nature of the disease., $32.2 \%$ believe that it is a genetic disease, $23.1 \%$ blame nutritional habits, $19.3 \%$ believe that preservatives and dye contents of certain types of the food are the main cause, $4.9 \%$ considered insecticides the main cause, $1.1 \%$ connected it to smoking and the rest believe that it is multi-cause disease.5.6\% of respondents believe that medical management is the main modality of treatment, $27.1 \%$ think that behavioral therapy is main treatment option and $59.8 \%$ suggested both modalities and the rest considered it as not a treatable disease.

Conclusion and Recommendations: Madina society is in a tremendous need to increase their awareness about ADHD in a simple layman language. 


\section{Introduction:-}

Attention Deficit Hyper-Active Disorder (ADHD) is one of the most common neurobehavioral developmental disorders among children. It has a special prevalence in preschool and early school years ${ }^{(1)}$ It is characterized by three main symptoms which are:persistent and debilitating inattention, over activityand impulsivity ${ }^{(2),(3)}$. Presently, there are three main subtypes of ADHD which are classified to: primarily inattentive (50-75\%), primarily hyperactive/impulsive (20-30\%) and a combined subtype (less than 15\%). ${ }^{(4)}$

ADHD may associate with a different psychiatric comorbidities as disruptive behavior disorders, anxiety and/or mood disorders. ${ }^{(5)}$ Additionally, to psychiatric, ADHD could be compound with difficulty in learning and socialemotional development ${ }^{(6)}$.

Epidemiological knowledge of ADHD was estimated in different countries by several studies on children between the ages of 6 and 12 years $^{(7)}$. The prevalence of ADHD in the US was 4-8\% ${ }^{(8), \text { (9) }}$. While in Korea it was between $7.6 \%$ to $9.5 \%{ }^{(10)}$. However, the prevalence was reached $20 \%$ in $\operatorname{India}^{(11)}$.

On the other hand, the prevalence rate of ADHD in all Arabic countries in general was ranging from $1.3 \%$ to $16 \%$ in one study ${ }^{(12)}$.

However, the prevalence in other studies like the one conducted in Qatar it showed that incidence of ADHD 9.4\% to $18 \%$ in Qatar. While, a similar study in the United Arab Emirates, showed the prevalence as $14.9 \%{ }^{(13)}$. According to a local study which was conducted in Saudi Arabia,11.6\% is the prevalencerate of ADHD ${ }^{(14)}$.

The underlining etiology of ADHD includes several factors like genetic, dietary, and environmental. Nutritional factorsin particular, such as color agents whichhave been determined to raise the risk of $\mathrm{ADHD}^{(15)}$.

It is still argumentative whether or not there is a relation between ADHD and sugar consumption. As in Wolraich et al's study, where they found that dietary food with high sucrose had no significant effects on behavior and cognitive performance in children ${ }^{(16)}$.

The diagnosis of ADHD isusually controversial as concerns areexpressed by parents, teachers, healthcare professionals and the public as well.The diagnosis and treatment of ADHD in children will be dependent mainly on the knowledge and perspectives of every person around the child. The diagnosis and treatment of children with ADHD require a good participation and cooperation among the family and educational and health professionals to achieve a common goal ${ }^{(17),(18)}$.

There are two definitive treatment lines for those children; medications, behavioral therapy or even both ${ }^{(19)}$.

Many global studies involving different professionals (teachers, teacher trainees and general physicians) havedisplayed that the misconception about ADHD and its treatment is persistent ${ }^{(20)}$.

We plan to determine the awareness of the Saudi population about such a complex disease in order to improve the current practice and to contribute to the management of ADHD as the society is in need to play its role as well.

\section{Methodology:-}

A multi-items cross sectional survey was conducted.The study population and sampling included both genders from 15 years and above as we don't aim to determine the incidence of the disease but we would like to assess the general knowledge about it. We chose our sample using random sampling method. We excluded people living outside Madina region, and who did not match our target age. We chose the questionnaire as a collecting tool (electronic and paper based questionnaire). This questionnaire reached to our target group through social media as well as, in the public places, secondary school students, and finally university students.

The variables we have been considered were age, gender, specialty, and occupation. Those whom are in the medical field were excluded. Before starting with our observation process, we explained the purpose of our study. Validity and reliability has been taken into account. Pilot study and pre-test has been done to clarify any ambiguous question. 
Data were analyzed by the Statistical Package for the Social Sciences (SPSS) version 20 acquired by IBM for statistical analysis.

Frequency tables were used to present the distribution of nominal variables. Results were expressed in numbers and percentages of respondents to each question and presented in tables. Their responses to 9 different related question which were: "have you heard of ADHD?", "where did you get information about ADHD", their believes about whether ADHD is a real disease and its underlying etiology, their knowledge about underlying causes and their treatment preferences.

\section{Results:-}

\begin{tabular}{|l|l|l|l|}
\hline \multicolumn{2}{|l|}{} & & Percent \\
\hline & Male (\%) & 63.1 & \\
\cline { 2 - 4 } & Female (\%) & 36.9 & \\
\cline { 2 - 4 } & Age (range),(mode) & $15-50$ & $21-25$ \\
\hline & $\begin{array}{l}\text { Level of education } \\
\text { (mode),n 421. }\end{array}$ & & Secondary School \\
\hline
\end{tabular}

Table 1:- Sociodemographic data n (450),* graph 1.

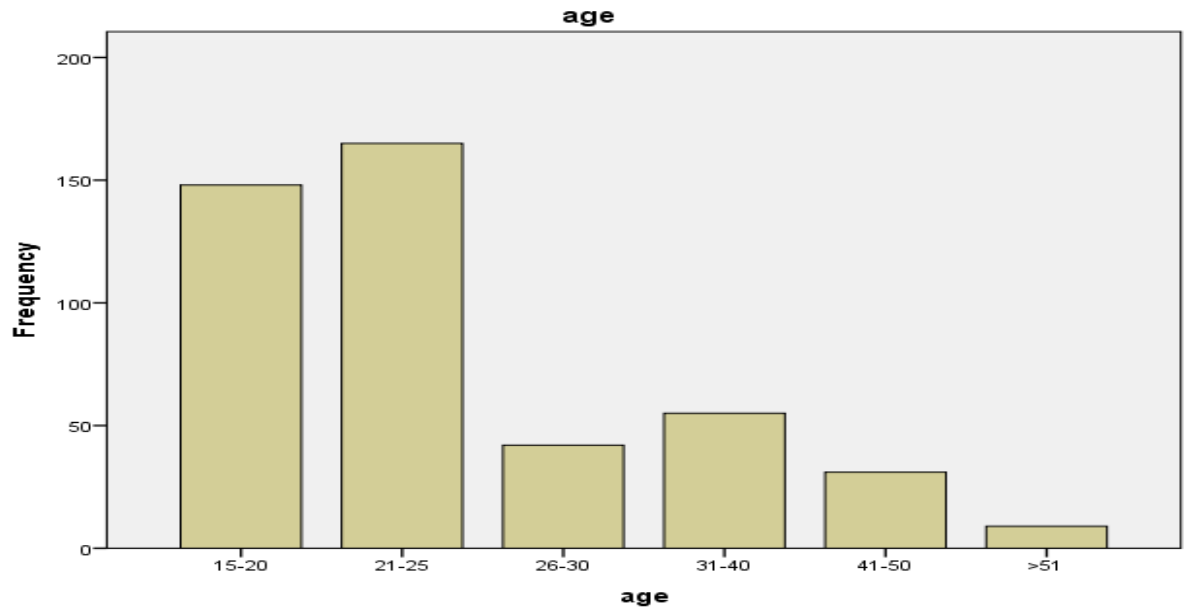

Graph 1: Age of the respondents.

Interestingly, approximately three-quarters of respondents had heard of ADHD, 373(71.8\%) and they were able to provide information about sources of their information. $25.1 \%$ knew the disease through their experience with an ADHD patient known to them. 14.7\% read about ADHD through medical websites, 7,3\% and $7.6 \%$ knew about it from newspapers and social media, respectively, 9\% didn't recall the source of their knowledge about it.

In addition, the majority of the sample, $71.3 \%$, believed that ADHD is a real disease, $22 \%$ believe that it is a behavioral disorder, $16 \%$ consider it as a neurological disease while $18 \%$ considered it as a psychiatric disorder. On the other hand, $31.8 \%$ believe that ADHD is a mixed disorder and only $11 \%$ did not know anything about the nature of the disease.

When asking the respondents about the underlying causes, $32.2 \%$ believe that it is a genetic disease, $23.1 \%$ blame nutritional habits, $19.3 \%$ believe that preservatives and dye contents of certain types of the food are the main cause, $4.9 \%$ considered insecticides the main cause , $1.1 \%$ connected it to smoking and the rest believe that it is multicause disease.

$5.6 \%$ of respondents believe that medical management is the main modality of treatment, $27.1 \%$ think that behavioral therapy is main treatment option and 59.8\% suggested both modalities and the rest considered it as not a treatable disease. 


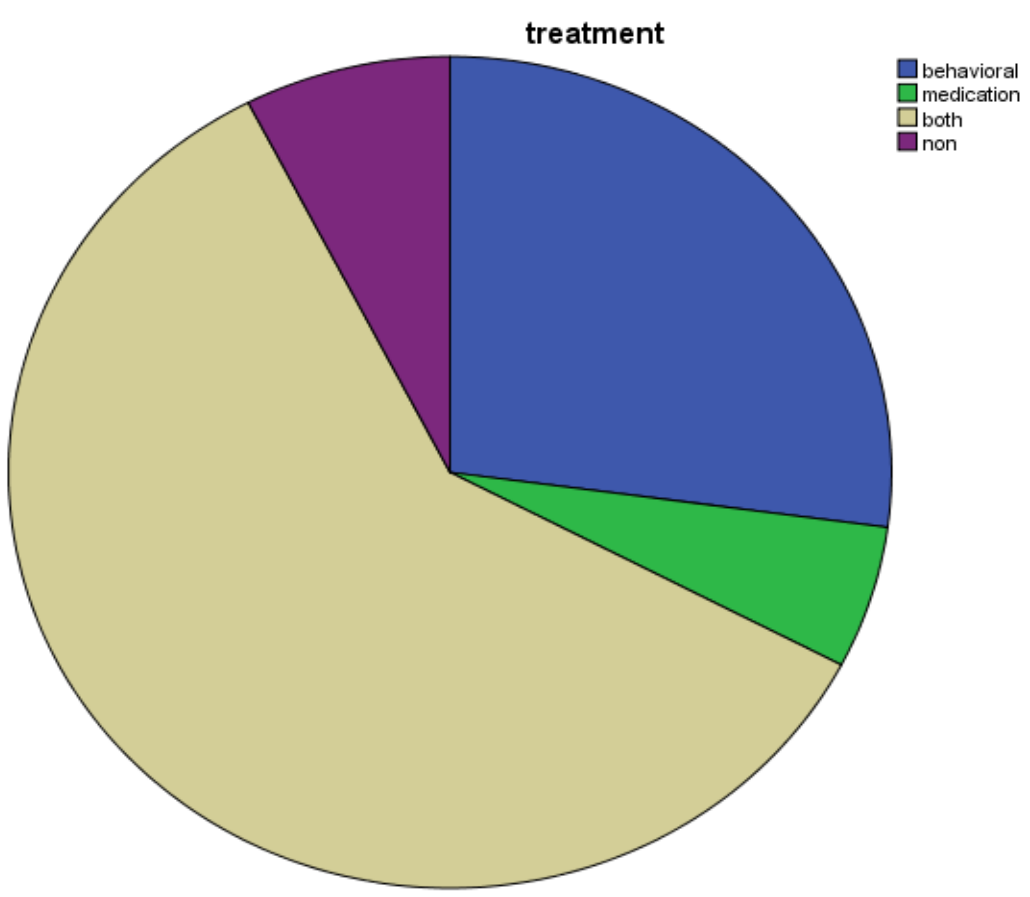

Graph 1: Believes of respondents about treatment options.

\section{Discussion:-}

Although a high percentage of participants in the study are young population and had a knowledge about ADHD, the vast majority of them didn't get the information from the ideal source as they get them through sharing experiences with others. This might reflect two things, first is how common is the problem second thing is the need to increase the awareness of how to seek more concise medical knowledge.

The good thing is that most of the participants are believing that ADHD is a disease and they believe in the importance of treatment.

\section{Recommendations:-}

Based on the results we have we believe that Madina society is in a tremendous need to increase their awareness about ADHD in a simple layman language.

\section{References:-}

1. American Psychiatric Association. Diagnostic and Statistical Manual of Mental Disorders. 4th ed. Washington, D.C.: American Psychiatric Association; 1994

2. Jo JI, Kim HK. Food habits and eating snack behaviors of middle school students in Ulsan area. Korean J Nutr 2008;41:797-808.

3. Oh KJ, Lee H. Assessment of ADHD with abbreviated Connersrating scale. Korean J ClinPsychol1989;8:13542

4. 4.Wilens, T. E., Biederman, J., \& Spencer, T. J. (2002). Attention deficit/hyperactivity disorder across the lifespan. Annual Review of Medicine, 53, 113-131.

5. Cantwell, D. P. (1996). Attention deficit disorder: a review of the past 10 years. Journal of the American Academy of Child and Adolescent Psychiatry, 35(8),978-987.

6. Biederman, J., Monuteaux, M. C., Doyle, A. E., Seidman, L. J., Wilens, T. E., Ferrero, F., et al. (2004). Impact of executive function deficits and attentiondeficit/hyperactivity disorder (ADHD) on academic outcomes in children. Journalof Consulting and Clinical Psychology, 72(5), 757-766.

7. Brown RT, Freeman WS, Perrin JM, Stein MT, Amler RW, Feldman HM, et al. Prevalence and assessment of Attention-Deficit/Hyperactivity Disorder in primary care settings. Pediatrics. 2001; 107(3):1-11 
8. National Center for Health and Disease Control and Prevention. CDC National Center on Birth Defects and Developmental Disabilities. ADHD:United States. (cited 2005 Jan 14). Available from: http://www.cdc.gov/ncbddd/adhd/databepi.htm.

9. Subcommittee on Attention-Deficit/Hyperactivity Disorder and Committee on Quality Improvement. Clinical Practice Guideline: Treatment of the school-aged child with attention-deficit/hyperactivity disorder. Pediatrics. 2001; 108:1033-44.

10. Chae PK, Jung HO, Noh K. Attention deficit hyperactivity disorder in Korean juvenile delinquents. Adolescence. 2001; 36(144): 707-25.

11. Malhi P, Singhi P. Spectrum of attention deficit hyperactivity disorders in children among referrals to $\begin{array}{llll}\text { psychology } & \text { services. } & \text { Indian } & \text { Pediatr. }\end{array}$ 37(11):1256-60.

12. Alhraiwil, N. J., Ali, A., Househ, M. S., Al-Shehri, A. M., \&El-Metwally, A. A. (2015). Systematic review of the epidemiology of attention deficit hyperactivity disorder in Arab countries. Neurosciences (Riyadh), 20, 137144.

13. Bu-Haroon, A., Eapen, V., \&Bener, A. (1999). The prevalence of hyperactivity symptoms in the United Arab Emirates. Nordic Journal of Psychiatry, 53, 439-442.

14. Al Haidar, F. (2002). Mental Retardation and Associated Psychiatric Disorders. Arab Journal of Psychiatry, 13(2), 111-117.

15. Schnoll R, Burshteyn D, Cea-Aravena J. Nutrition in the treatment of attention-deficit hyperactivity disorder: a neglected but important aspect. ApplPsychophysiol Biofeedback 2003;28:63-75.

16. Dykman KD, Dykman RA. Effect of nutritional supplements on attentional-deficit hyperactivity disorder. IntegrPhysiolBehavSci1998;33:49-60.

17. DeGrandpre RJ. Ritalin nation: rapid fire culture and the transformation of human consciousness. New York: W. W. Norton \&Company; 2000.

18. American Academy of Pediatrics, Project Advisory Committee .The medical home: medical home initiatives for children with special needs. Pediatrics. 2002;110:184-6.

19. Jensen, P. S., Arnold, L. E., Swanson, J. M., Vitiello, B., Abikoff, H. B., Greenhill, L. L., et al. (2007). 3 -year follow-up of the NIMH MTA study. Journal of the AmericanAcademy of Child and Adolescent Psychiatry, 46(8), 989-1002.

20. 4. Rodrigo MD, Perera D, Eranga VP, Williams SS, KuruppuarachchiKA. The knowledge and attitude of primary school teachers in Sri Lanka towards childhood attention deficit hyperactivity disorder. Ceylon Med J. 2011;56:51-4. 